\title{
What goes up must come down: The burden of bipolar depression in youth
}

\author{
Anna R. Van Meter, \\ University of North Carolina at Chapel Hill, Department of Psychology \\ David B. Henry, and \\ University of Illinois at Chicago, Institute for Health Research and Policy \\ Amy E. West \\ University of Illinois at Chicago, Departments of Psychology and Psychiatry
}

\begin{abstract}
Background-In the pediatric bipolar disorder literature, mania has eclipsed depression as the mood state of most interest. Though depressive episodes tend to be more prevalent and persisting than manic episodes, research about the associated consequences is limited. The goal of the present study was to compare the influences of depressive and manic symptoms on domains of functioning in which youth with bipolar disorder often demonstrate deficits.
\end{abstract}

Method-Youth meeting DSM-IV-TR criteria for bipolar spectrum disorders (I, II, and NOS) between the ages of seven and 13 were recruited from a clinic in a large Midwestern city $(N=54)$. Both parent and clinician report of manic and depressive symptoms were used in regression analyses to determine how each set of symptoms was related to child functioning.

Results-Parent-rated child depression symptoms were associated with problem behaviors ( $p<$. $05)$, and lower quality of life $(p<.001)$. Clinician-rated child depression was associated with greater psychiatric illness $(p<.05)$, lower child self-concept $(p<.001)$, lower quality of life $(p<.05)$, hopelessness $(p<.05$, and suicidal ideation ( $p<.05)$. Parent-rated mania was associated with better self-esteem $(p<.05)$ and physical wellbeing $(p<.05)$. Clinician-rated mania was associated with greater psychiatric illness $(p<.05)$ and physical wellbeing $(p<.05)$.

Limitations-The specific outcomes predicted by parent and clinician-rated symptoms vary. Though the overall story told - that bipolar depression is associated with significant impairment in youth - is consistent, further research is necessary to more fully understand the impact of each mood state.

(C) 2013 Elsevier B.V. All rights reserved.

Corresponding Author: Amy E. West, Department of Psychiatry, Institute for Juvenile Research, University of Illinois at Chicago, 1747 W. Roosevelt Rd, MC 747, Chicago, IL 60608, (312) 996-1077, awest@psych.uic.edu.

This is a PDF file of an unedited manuscript that has been accepted for publication. As a service to our customers we are providing this early version of the manuscript. The manuscript will undergo copyediting, typesetting, and review of the resulting proof before it is published in its final citable form. Please note that during the production process errors may be discovered which could affect the content, and all legal disclaimers that apply to the journal pertain.

Conflicts of Interest

The authors have no financial interests or other conflicts of interest to disclose.

Contributors

Ms. Van Meter and Dr. West conceptualized the study. Ms. Van Meter managed the literature review, performed the analyses, and wrote the manuscript. Dr. Henry provided statistical consultation. Both Dr. Henry and Dr. West provided comments on the manuscript. All authors contributed to, and have approved, the final manuscript. 
Conclusion-Mania is undoubtedly destructive, but this study provides evidence to suggest that depression may be more deleterious to youths' psychosocial functioning and quality of life; more attention to understanding and ameliorating the effects of bipolar depression on youth is warranted.

\section{Keywords}

Pediatric bipolar disorder; depression; mania; quality of life; impairment

Pediatric bipolar disorder (PBD) has been the subject of increasing interest, both in research and in popular culture. However, the attention focused on PBD has not been allocated equally to the two poles of bipolar disorder; pediatric mania, characterized by extreme lability of mood, irritability, and potentially dangerous behaviors, has far eclipsed bipolar depression as the mood state of most interest to industry, researchers, and the media. Among the research questions posed about pediatric mania are - does it exist at all? If so, how do we best define it? What are the most efficacious and safe treatments (Biederman et al., 2000; B Geller et al., 2002; Kowatch, Youngstrom, Danielyan, \& Findling, 2005; Soutullo et al., 2005; Wozniak et al., 1995)? The burst of research activity to address these questions appears to run parallel with a controversial rise in clinical diagnoses (Moreno et al., 2007) and in the prescription of mood stabilizing and anti-psychotic mediations (Olfson, Blanco, Liu, Moreno, \& Laje, 2006; Zito et al., 2003)

In contrast, there are only a handful of investigations that address bipolar depression in youth. This fact is not hard to understand; from a research perspective, pediatric mania is a relatively new concept, and the task of defining and treating the extreme behaviors associated with mania in kids is an exciting challenge. Another factor that likely promotes the focus on mania is that parents are more likely to bring their child to a clinic for externalizing behaviors than for internalizing (Lynch \& Clarke, 2006); symptoms of mania are "garlic" symptoms - they bother everyone else - whereas depressive symptoms are "onion" symptoms - they primarily bother the individual (Freeman, Youngstrom, Freeman, Youngstrom, \& Findling, 2011). Both clinically and in research, mania has been the "squeaky wheel" of bipolar disorder symptoms in youth (Cosgrove, Roybal, \& Chang, 2013).

A similar imbalance exists in the adult literature, with greater resources going to the study and treatment of mania than bipolar depression (Michalak, Murray, Young, \& Lam, 2008); however, data suggest that this disparity is unjustified. In studies of adults, those with bipolar I tend to spend more than three times as many weeks depressed than manic or hypomanic (Kupka et al., 2007). Furthermore, recovery from episodes of bipolar depression tends to be slower than from manic episodes (Michalak, et al., 2008; Post, 2005). The sparse data on bipolar depression in youth suggest a similar story; depressive episodes tend to be both more prevalent and more persisting than episodes of mania (Birmaher, Axelson, Goldstein, et al., 2009; Birmaher, Axelson, Strober, et al., 2009; Cosgrove, et al., 2013). Additionally, the symptoms of bipolar depression tend to become more severe as youths age; adolescent bipolar depression is associated with higher levels of guilt, social withdrawal, appetite changes, rejection sensitivity, and suicidality (Birmaher, Axelson, Strober, et al., 2009).

The literature on unipolar depression in young people dates back over 100 years (Trumbull, 1898), but these research suggests that these findings cannot be generalized to bipolar depression. Qualitative differences exist between unipolar and bipolar depression in youth (Wozniak et al., 2004), including atypical symptoms such as psychomotor changes and mood lability (Bowden, 2001). Additionally, there is ongoing debate about whether or not it 
is safe and efficacious to use antidepressants in the treatment of bipolar depression (Joseph, Youngstrom, \& Soares, 2009; Licht, Gijsman, Nolen, \& Angst, 2008; Nivoli et al., 2011; Sidor \& MacQueen, 2011; Tondo, Vazquez, \& Baldessarini, 2010), consequently, clear guidelines on evidence-based treatments for bipolar depression are limited (Cosgrove, et al., 2013).

An important reason for investigating bipolar depression, in addition to unipolar depression, is that subtle differences in the two illnesses may enable early detection and intervention. Most cases of pediatric bipolar disorder begin with a depressed mood episode (Birmaher, Axelson, Goldstein, et al., 2009; Birmaher et al., 2006), and up to 50\% of youth initially diagnosed with depression go on to develop a bipolar spectrum disorder (Cosgrove, et al., 2013; Geller, Zimmerman, Williams, Bolhofner, \& Craney, 2001; Strober, 1993), Administering the right treatment early on may result in a more positive prognosis for youth with bipolar disorder (Birmaher \& Brent, 2007; Chang, 2008; Post, 2005). On the other hand, there is concern that the wrong treatment (Baumer et al., 2006), or no treatment, may lead to more days ill, may contribute to "kindling," and can result in higher levels of comorbid disorders (McElroy, Strakowski, West, Keck, \& McConville, 1997; Post, 2007; Schraufnagel, Brumback, Harper, \& Weinberg, 2001).

A public health approach also supports the examination of bipolar depression; indeed, it is during episodes of bipolar depression, rather than mania, that a person is most likely to attempt suicide (Dilsaver et al., 1997). Depression is thought to be a primary risk factor for suicide in youth, but studies in adults suggest that bipolar depression likely confers even greater risk than unipolar depression (Mitchell \& Malhi, 2004), and as many as $40 \%$ of youth with bipolar disorder will attempt suicide by age 18 (Lewinsohn, Seeley, \& Klein, 2003). Additionally, depression severity has been shown to be a significant predictor of suicide attempt, among youth with bipolar disorder, but mania has not (Goldstein et al., 2005).

Pediatric bipolar disorder is associated with significant impairment and reduced quality of life (Freeman et al., 2009; Keenan-Miller, Peris, Axelson, Kowatch, \& Miklowitz, 2012). Because there is so little research examining bipolar depression in youth, we do not know its full impact, nor can we parse apart the unique effects of depression and mania on young people. The aim of the present study is to gain a better understanding of the relation between bipolar depression and mania in youth, and to describe the impact of symptoms of each mood state on behavior and functioning. Specifically, we sought to assess the independent influence of depressive symptoms and of manic symptoms on domains in which youth with bipolar disorder often exhibit problems, including disruptive behaviors, self-concept, hopelessness, relationship quality, school performance, and suicidality

\section{Method}

\section{Participants}

Fifty-four participants were recruited from a specialty mood disorders clinic in a large Midwestern city as part of a randomized controlled trial of child- and family-focused cognitive behavioral therapy (CFF-CBT) for pediatric bipolar disorder. Youth meeting DSM-IV-TR criteria for bipolar spectrum disorders (I, II, and NOS) between the ages of seven and 13 were eligible to participate. Youth who had an IQ lower than 70, were actively psychotic, had serious neurologic or medical problems, or met criteria for active substance abuse or dependence were excluded. Additionally, youth whose primary caretaker was experiencing a current episode of depression or mania were not included. 
The sample had an average age of $9.1(S D=1.59)$. Forty-two percent were female; $60 \%$ European Caucasian, 29\% African American, 5 \% Hispanic, 4\% American Indian or Alaskan, and $2 \%$ identified as "Other." Forty-one percent of the sample was diagnosed with bipolar I, $2 \%$ with bipolar II, and 57\% bipolar disorder not otherwise specified. Thirty-three percent had a comorbid anxiety disorder, $74 \%$ had comorbid ADHD, 39\% had comorbid oppositional defiant disorder, and $4 \%$ had comorbid conduct disorder. Nearly half of the sample $(46 \%)$ reported their current or most recent episode as mixed, $27 \%$ reported manic, $2 \%$ hypomanic, $6 \%$ depressed, and 19\% did not specify. See Table 1.

\section{Measures}

\section{The Washington University Schedule for Affective Disorders and} Schizophrenia-(WASH-U-KSADS; Geller, Williams, Zimerman, \& Frazier, 1996) is a semistructured interview used with both youth and their parents to make a DSM-IV diagnosis (American Psychiatric Association, 1994). The WASH-U-KSADS was specifically designed to assess for bipolar disorder in young people and includes special sections to better identify developmentally-specific symptoms of mania and depression, and mood episodicity. Research assistants were trained to administer the interview and met stringent reliability criteria (kappa >.90).

The Children's Global Assessment Scale-(C-GAS; Shaffer et al., 1983) is a clinician-rated measure of child functioning based on impairment of adaptation in family, social, school, and work areas due to psychiatric symptoms. Scores fall on a specified continuum of health-illness, which ranges from 1-100, higher scores indicate better overall functioning. Inter-rater reliability has been found to be moderate with an intraclass correlation coefficient of 0.73 (Lundh, Kowalski, Sundberg, Gumpert, \& Landen, 2010).

The Children's Global Impressions Scales for Bipolar Disorder-(CGI-BP; Spearing, Post, Leverich, Brandt, \& Nolen, 1997) is a clinician report of the severity of a child's overall psychiatric illness severity. Scores are calculated by summing scores across the subscales (mania, depression, attention deficit/hyperactivity, psychosis, and sleep difficulties); inter-rater reliability for youth not experiencing an acute mood episode is 0.75 (Spearing, et al., 1997).

The Young Mania Rating Scale-(YMRS; Young, Biggs, Ziegler, \& Meyer, 1978) is a clinician-rated measure of the severity of a child's manic symptoms. The scale consists of 11 items, which are summed to create a severity score. The scale has shown good reliability and validity in past studies (Fristad, Weller, \& Weller, 1992; Fristad, Weller, \& Weller, 1995; R. Young, et al., 1978), the reliability in the present study was 0.61 (Cronbach's alpha).

The Children's Depression Rating Scale-Revised-(CDRS-R; Poznanski, Freeman, \& Mokros, 1985; Poznanski et al., 1984) is a clinician-rated instrument for measuring the severity of depression in children. Scores are calculated by summing scores across 17 items that assess depressive symptoms, each of which is rated on a 5-point Likert-type scale. The reliability for this scale in this sample was good, Cronbach's alpha $=0.81$.

The Child Mania Rating Scale-(CMRS; Pavuluri, Henry, Devineni, Carbray, \& Birmaher, 2006) is a parent-rated measure for symptoms of mania, such as elevated mood, increased motor activity, hypersexual interest, lack of sleep, irritability, tangential language and pressured speech, and aggressive behavior, with high inter-rater reliability and concurrent validity with other mania rating scales. Scores are calculated by averaging scores across the 21 items assessing mania, each of which are rated on a Likert scale ranging from 
0 (never) to 3 (very often). The reliability for this scale is strong in this sample, Cronbach's alpha $=0.90$.

The Child Bipolar Depression Rating Scale-(CBDRS; Pavuluri, unpublished) is a companion measure to the Child Mania Rating scale. This parent report includes 22 items that assess for symptoms of depression in youth, as defined by DSM-IV-TR criteria. The scale is face valid and has high reliability (Cronbach's alpha=0.88) in this sample.

The Eyberg Child Behavior Inventory-(ECBI; Burns \& Patterson, 2001; Eyberg \& Ross, 1978) assesses parents' report on their child's problem behaviors. The instrument consists of 36 questions, which measure both the frequency of behaviors and how problematic the parent finds these behaviors. This scale can be used to accurately assess conduct-problem behavior in children. In this sample, the reliability for the frequency of problem behaviors scale had good reliability (Cronbach's alpha=0.80), as did the intensity of problems scale (Cronbach's alpha=0.89).

Piers-Harris Self-Concept Scale-(PHSCS-2; Piers, Harris, \& Herzberg, 2002; Piers \& Herzberg, 1969) is a questionnaire, completed by the child, that measures attitudes about physical appearance, anxiety, intellectual and school status, behavior, satisfaction with self, and popularity. The PHSCS- 2 consists of 60 statements, which the child rates either yes or no, and yields both a total score and scores for each subscale. The reliability in this sample was 0.84 (Cronbach's alpha).

\section{The Questionnaire for Measuring Health-Related Quality of Life in Children-}

(KINDL; Ravens-Sieberer \& Bullinger, 2000) measures quality of life in children, using six subcategories: physical, emotional, self-esteem, family, friends, and school. This questionnaire was designed to evaluate quality of life in both healthy children and children who suffer from health (mental and physical) problems. The measure has both a parent report and a child self-report, and offers different versions in order to appropriately assess youth of different ages. It consists of 24 items, evaluated on a 5-point Likert scale, and has demonstrated excellent validity in previous studies (Bullinger, Brütt, Erhart, \& RavensSieberer, 2008; Freeman, et al., 2009; Wee, Lee, Ravens-Sieberer, Erhart, \& Li, 2005). The reliability for the parent scale was Cronbach's alpha $=0.83$, and for the child scale was Cronbach's alpha $=0.73$.

Hopelessness Scale for Children-(HSC; Kazdin, Rodgers, \& Colbus, 1986) is a child self-report. It consists of 17 items that children identify to be true or untrue of them. A high score on this measure reflects increased feelings of hopelessness and negative expectations toward the future. Both reliability and validity have been strong in previous studies (Spirito, Williams, Stark, \& Hart, 1988). Reliability in the present study was adequate (Cronbach's alpha $=0.65)$.

The Columbia Suicide Severity Rating Scale-(C-SSRS; K Posner et al., 2008) is a clinician-administered scale that assesses suicidal behavior and ideation over both the participant's life and the past 7 days. It has shown good sensitivity and specificity for suicidal behavior across multiple studies, with internal consistency of 0.73 across patient visits (Posner et al., 2011). For the present study, we will be using items from the scale as dependent variables in binary form (present/not present) to determine whether or not mood symptoms predict suicidal ideation, ideation with a method, ideation with intent, ideation with a plan, suicidal behavior, or suicide attempt. 


\section{Procedure}

All study procedures were approved by the IRB. After the informed consent procedure, each youth and parent were interviewed separately using the WASH-U-KSADS (Geller, et al., 1996). Following determination that the diagnostic criteria for a bipolar spectrum disorder were met, the participant and his/her parent each completed a series of questionnaires. Past research has shown that parent and clinician reports about a child and his/her symptoms often differ (Bastiaansen, Koot, Ferdinand, \& Verhulst, 2004; Youngstrom, Findling, \& Calabrese, 2003, 2004). Consequently, in the present study, parent and clinician report were included separately as independent variables in the regression analyses.

Analytic plan-We used regression analyses to investigate the hypothesis that depressive symptoms would account for variance in scale scores related to disruptive behaviors, child self-concept, relationship quality, school performance, overall youth quality of life, and hopelessness. In each regression model, demographic variables (age, gender, and presence or absence of bipolar I diagnosis) were entered first, followed by the symptom scales. Parent and clinician-reported mania and depression scales were entered in separate analyses. Additionally, a two-way interaction term for mania and depression was included to determine whether co-occurring manic and depressive symptoms more strongly predicted the outcomes. Univariate logistic regression was used to investigate the relation between depressive symptoms, manic symptoms, and the binary suicide outcome variables. The logistic regression included the same control variables and independent variables.

\section{Results}

\section{Preliminary Analyses}

We used percent of maximum possible scoring (Cohen, Cohen, Aiken, \& West, 1999) to rescale both the parent- and clinician-rated mood scales on a $0-100$ scale. The characteristics of each of the symptom scales and the total scores for the outcome subscales are described in Table 2 (descriptive statistics for all the subscales, including correlations between scales are available upon request).

\section{Primary Analyses}

Analyses were planned to provide information regarding how manic and depressive symptoms related to the outcome variables. $R^{2}$ values were calculated to determine the variance in each outcome variable explained by each symptom scale, and correlational analyses (Hotelling's $t$-test) allowed us to examine the magnitude of the relations between the symptom scales and the outcome variables. These tables are available upon request from the authors. Though both parent- and clinician-rated scores were used to predict each outcome variable of interest, only significant findings are presented.

Severity of illness-We examined the relation between C-GAS and CGI scores and both parent- and clinician-rated symptoms of mania and depression. Clinician-rated mania $(\beta=$ $0.40, p<.01)$ and depression $(\beta=0.32, p<.05)$ were significant predictors of the CGI overall psychiatric illness severity scale, more severe symptoms were associated with more severe psychiatric illness.

Problem behaviors-Parent-reported depression was associated with higher scores on the ECBI Intensity Scale $(\beta=0.51, p<.05)$, indicating that depressive symptoms were associated with increased intensity of child's problem behaviors. Higher scores on the clinician-rated depression scale were associated with lower scores on the ECBI problem scale $(\beta=-0.47, p<.05)$, indicating fewer total problem behaviors. There was no relation between manic symptoms and the ECBI scales. 
Child self-concept-Parent-rated depression was associated with lower scores on the child-reported PHSCS happiness and satisfaction $(\beta=-0.39, p<.05)$ scales. Additionally, the interaction term for parent-rated mania and depression was associated with lower anxiety ( $\beta=0.38, p<.05)$, better behavioral adjustment $(\beta=0.35, p<.05)$, and with better overall self-concept $(\beta=0.35, p<.05)$. These interactions indicate that the severity of manic symptoms moderated the association between depression and poorer self-concept.

Higher clinician-rated depression scores predicted lower scores on the PHSCS intellectual and school status scale $(\beta=-0.30, p<.05)$, higher anxiety scores $(\beta=-0.57, p<.001)$, and scores consistent with lower popularity $(\beta=-0.50, p<.05)$, poorer behavioral adjustment $(\beta$ $=-0.58, p<.001)$, lower happiness and satisfaction $(\beta=-0.59, p<.001)$, and lower overall self-concept $(\beta=-0.58, p<.001)$.

Quality of life-Parent-rated mania scores were related to the child-rated KINDL scale for self-esteem $(\beta=0.45, p<.05)$. Mania scores also predicted parent-rated KINDL physical wellbeing ( $\beta 0.43, p<.05)$, indicating better physical health. Parent-rated depression scores were related to the child-rated KINDL scale for physical wellbeing $(\beta=-0.43, p<.05)$, and overall quality of life $(\beta=-0.46, p<.05)$, and to the parent-rated KINDL scale for physical wellbeing ( $\beta=-0.71, p<.05)$, emotional wellbeing $(\beta=-0.80, p<.001)$, self-esteem $(\beta=$ $-0.44, p<.05)$, family functioning $(\beta=-0.46, p<.001)$ and overall quality of life $(\beta=-0.75$, $p<.001$ ), indicating lower functioning across these domains. The interaction term for parentrated mania and depression was related to the child-rated KINDL family functioning scale ( $\beta=0.36, p<.05)$ indicating better family functioning for individuals with both severe manic and depressive symptoms, as compared to youth with more severe depression.

Clinician-rated mania scores were related to higher scores on the child-rated KINDL scale for physical wellbeing $(\beta=0.32, p<.05)$. Clinician-rated depression scores were related to lower scores on child-rated KINDL scales for physical wellbeing $(\beta=-0.35, p<.05)$, emotional wellbeing ( $\beta=-0.33, p<.05)$, self-esteem $(\beta=-0.45, p<.01)$, family function ( $\beta$ $=-0.38, p<.05)$, friendship quality $(\beta=-0.31, p<.05)$, school function $(\beta=-0.41, p<.01)$, and overall quality of life $(\beta=-0.62, p<.001)$. Clinician-rated depression was also associated with lower scores on the parent-rated KINDL overall quality of life $(\beta=-0.29$, $p<.05)$.

The interaction term for clinician-rated mania and depression was related to higher scores on the KINDL emotional wellbeing scale $(\beta=0.56, p<.05)$, suggesting that though higher scores on the CDRS predict lower emotional wellbeing, comorbid mania may be protective. The clinician-rated interaction term was also associated with higher scores on the parentrated school functioning scale $(\beta=0.33, p<.05)$.

Hopelessness-Clinician-rated depression scores were associated with higher levels of hopelessness $(\beta=0.47, p<.05)$; children who were more depressed reported greater hopelessness.

Suicidality-The only parent-reported scale associated with suicidality was the interaction term for the CMRS and CBDRS, which predicted a reduction in lifetime active suicidal ideation $(\mathrm{OR}=0.99, p<.05)$. Clinician-rated depression scores, on the other hand, predicted lifetime active suicidal ideation $(\mathrm{OR}=1.10, p<.05)$, ideation with method in mind $(\mathrm{OR}=$ $1.12, p<.05)$, lifetime ideation with intent $(\mathrm{OR}=1.13, p<.05)$, and lifetime ideation with a plan $(\mathrm{OR}=1.13, p<.05)$. Clinician-rated depression was not predictive of suicide attempt. These analyses were conducted after eliminating the item from the CDRS that specifically inquires about suicidal ideation. 


\section{Discussion}

The present study set out to examine how symptoms of mania and of bipolar depression impact the lives of youth with bipolar disorder. Though mania - its phenomenology, impact, and treatment - has dominated the pediatric bipolar disorder literature, this study provides evidence that the low moods of bipolar disorder may be more insidious and impairing than the high.

We hypothesized that the impact of bipolar depression in youth would be significant, but the lopsided nature of the results was more striking than expected; across numerous measures, depression was a significant predictor of negative outcomes, mania was not. This is not to say that mania is not impairing, our sample included only youth with bipolar disorder, so we cannot comment on the degree to which mania and/or depression caused problems for youth with bipolar disorder, relative to youth without mood disturbance. Still, at the very least, these findings suggest that the collective focus on mania, often it seems at the exclusion of depression, may be misguided.

The associations found between manic symptoms and some positive outcomes were surprising. Specifically, for a number of outcomes, the interaction of mania and depression predicted positive results, whereas depression alone predicted the opposite. Given the generally bleak picture of pediatric mania, it is intriguing to think about ways in which this mood state may protect against the darkness of its opposite, depression. Studies of adults with bipolar disorder have highlighted differences in "sunny" versus "dark" manifestations of mania (Akiskal, Hantouche, \& Allilaire, 2003). Though we are not aware of any similar investigations in youth, the results of this study suggest that there could be positive aspects of pediatric mania that are worth exploring.

Based on the attention paid to the externalizing symptoms of mania - tantrums, restlessness, irritability, aggression - it is noteworthy that neither the parent- nor clinician-rated manic symptom scales showed a relation with the ECBI measures of problem behaviors, with poor functioning (school, peer or family, as measured by the KINDL), or with overall impairment according to the C-GAS. These are the realms in which we most expect mania to wreak havoc; even in youth experiencing high levels of manic symptoms, the negative impact of mania, over that of depression, on functional outcomes was not significant. On the contrary, the interaction term for mania and depression, as rated by the clinician, was associated with higher scores on the emotional wellbeing child-rated KINDL scale and on the parent-rated school functioning KINDL scale. Similarly, the parent-rated interaction term for mania and depression was associated with lower anxiety, better behavioral adjustment, better overall self-concept, and better child-rated family functioning.

It was surprising that parent report of child's depression, rather than mania, was predictive of the intensity of the child's behaviors, as rated on the ECBI Intensity Scale, which asks parents "how problematic" they find various behaviors in which their child engages. Clinician-reported depression was also related to problem behaviors (number, rather than intensity). This is counterintuitive; though we associate mania with problem behaviors of great intensity, these results suggest that, above and beyond the impact of mania on a child's behavior, depression has a negative effect. Depression may not be a primary predictor of physical aggression or lying and stealing, but we might be reminded that distractibility, anxious behaviors, irritability, restlessness, and other characteristics of depression are also impairing to both a child and his/her family.

The outward expressions of depression captured on the ECBI may be thought of as the tip of the depression iceberg; the impact on the child's self-concept, across numerous domains, was significant. Clinician ratings of child depression were predictive of worse scores on the 
PHSCS scales for Intellectual and School Status, Freedom from Anxiety, Popularity, Behavioral Adjustment, Happiness and Satisfaction, and overall Self-Concept. This paints a grim picture of how youth with bipolar depression see themselves; such a negative perspective could limit the initiation and maintenance of positive relationships, opportunities for academic success, and involvement in positive activities. In a study of adults, Power et al (2002) found that people with bipolar disorder tend to "compartmentalize" their selfconcept, imagining themselves in completely positive or completely negative terms. If this is also true for youth, as our study suggests, psychosocial treatment to challenge cognitive distortions may be an important aspect of ameliorating the negative consequences of bipolar depression. Unfortunately, the bulk of treatment literature for pediatric bipolar disorder has focused on pharmacological treatments aimed at mania.

Clinician-rated depression scores were also associated with poorer physical wellbeing, emotional wellbeing, self-esteem, family function, friendship quality, school function, and overall quality of life, as rated by the child. Similarly, parent-rated depression scores predicted poorer physical wellbeing and overall quality of life, as rated by the child, and poorer scores on the parent KINDL scale for overall quality of life. This gives a sense for the scope of the impact of bipolar depression, and replicates a previous study (Freeman, et al., 2009), which found that the effect of depressive symptoms was greater than that of manic symptoms on all quality of life scales.

The finding that CDRS scores predicted greater child-reported hopelessness was consistent with our initial hypothesis. Related, CDRS scores were also associated with suicidal ideation - passive, with a method, with intent, and with a plan. Though the relation between depressive symptoms, including hopelessness, and suicidal ideation is not surprising, the high rates of suicidality in this young sample - 76\% - again highlights the potential consequences of failing to notice and effectively treat bipolar depression.

Mania is undoubtedly destructive, but this study provides evidence to suggest that depression may be more deleterious to youths' quality of life. Between our findings, and those from adult studies, the evidence is mounting that bipolar depression is associated with myriad negative outcomes, including problem behaviors, hopelessness, poor quality of life across multiple domains, and suicidal ideation and behaviors. We know that a youth diagnosed with bipolar disorder is likely to spend more days depressed than manic, and that negative effects of depression will accumulate over time. Though perhaps not as behaviorally salient as the characteristics associated with mania in youth, the symptoms of bipolar depression cause real harm, and deserve greater attention from the research community.

Most treatment studies for pediatric mania have focused on controlling manic symptoms, and there is concern about prescribing anti-depressants (Cosgrove, et al., 2013; Joseph, et al., 2009; Licht, et al., 2008; Nivoli, et al., 2011; Sidor \& MacQueen, 2011; Tondo, et al., 2010); but it may be that some of the detrimental effects of bipolar depression could be eliminated with adequate treatment. These findings highlight the importance of incorporating psychotherapy into treatment guidelines for pediatric bipolar disorder; many of the therapies designed for youth with bipolar disorder include depression-specific targets (West et al., 2009; Young \& Fristad, 2007) and have been shown to be effective at improving depressive symptomatology (Cosgrove, et al., 2013; Goldstein, Axelson, Birmaher, \& Brent, 2007; Miklowitz et al., 2004). Research focused on treatments designed to best ameliorate the symptoms, and negative consequences, associated with both bipolar depression and mania will offer a significant contribution to the field. 


\section{Limitations}

We included both clinician and parent report of symptoms, and clinician, parent, and child report of outcomes, in an effort to capture different perspectives on symptom severity and impact. Though the overall story told - that bipolar depression is associated with significant impairment in youth - is consistent, the specific outcomes predicted by parent and clinicianrated symptoms vary. For the present study, clinicians were trained to take both child and parent report into account when making their ratings, which may explain some of the discrepancy between parent and clinician measures. Previous research has found that the correspondence between parent and child report of depressive symptoms is often low, and that child report may be more valid (Cantwell, Lewinsohn, Rohde, \& Seeley, 1997; Alan E. Kazdin, French, Unis, \& Esveldt-Dawson, 1983; Moretti, Fine, Haley, \& Marriage, 1985). Parent report, on the other hand, may be better at discriminating manic symptomatology (Youngstrom, Findling, \& Calabrese, 2004; Youngstrom et al., 2004). We hope that, by training clinicians to consider both self-report and interview data from both parent and child, we have overcome some of the limitations of relying solely on self-report data.

Disagreement between reporters may have been exacerbated by temporal issues in the present study. The YMRS asks clinicians to rate current symptoms of mania, the CMRS, on the other hand, is broader in its time scope, asking "Does your child..." The CBDRS and CDRS do not define a specific time frame, consequently, depending on interpretation of the questions, the results may describe current, past, or lifetime symptoms. Similarly, the outcome measures vary in terms of the time period asked about; in youth with oft-changing moods, symptoms measured today may not be good at predicting something that happened last month.

\section{Conclusion}

We refer to depression and mania in general terms, but each mood label stands for a heterogeneous group of symptoms, and cases of pediatric bipolar disorder often have as many differences as commonalities. Which specific aspects of bipolar depression cause decreased quality of life and through what mechanisms mania provides protection against functional impairment remain important areas for study. In general, the identification of how different symptom constellations in PBD relate to functional impairment should be an important mission for our research agenda. Thus, this study introduces new questions to guide researchers in developing a more in-depth understanding of this complex disorder and raises awareness of the debilitating effects of bipolar depression in youth.

\section{Supplementary Material}

Refer to Web version on PubMed Central for supplementary material.

\section{Acknowledgments}

We thank the families who participated in this research.

Role of Funding Source

This study was funded by NIMH \# 1K23-MH079935, awarded to Amy E. West.

\section{References}

Akiskal H, Hantouche E, Allilaire JF. Bipolar II with and without cyclothymic temperament: "dark" and "sunny" expressions of soft bipolarity. Journal of Affective Disorders. 2003; 73(1-2):49-57. [PubMed: 12507737] 
American Psychiatric Association. Diagnostic and Statistical Manual of Mental Disorders. Fourth ed.. Washington, DC: American Psychiatric Association; 1994.

Bastiaansen D, Koot HM, Ferdinand RF, Verhulst FC. Quality of Life in Children With Psychiatric Disorders: Self-, Parent, and Clinician Report. Journal of the American Academy of Child and Adolescent Psychiatry. 2004; 43(2):221-230. [PubMed: 14726730]

Baumer F, Howe M, Gallelli K, Simeonova D, Hallmayer J, Chang K. A pilot study of antidepressantinduced mania in pediatric bipolar disorder: Characteristics, risk factors, and the serotonin transporter gene. Biological Psychiatry. 2006; 60(9):1005-1012. [PubMed: 16945343]

Biederman J, Mick E, Faraone S, Spencer T, Wilens T, Wozniak J. Pediatric mania: A developmental subtype of bipolar disorder? Biological Psychiatry. 2000; 48(6):458-466. [PubMed: 11018219]

Birmaher B, Axelson D, Goldstein B, Strober M, Gill MK, Hunt J, Keller M. Four-year longitudinal course of children and adolescents with bipolar spectrum disorders: The course and outcome of bipolar youth (COBY) study. American Journal of Psychiatry. 2009; 166(7):795-804. [PubMed: 19448190]

Birmaher B, Axelson D, Strober M, Gill MK, Valeri S, Chiappetta L, Keller M. Clinical course of children and adolescents with bipolar spectrum disorders. Archives of General Psychiatry. 2006; 63(2):175-183. [PubMed: 16461861]

Birmaher B, Axelson D, Strober M, Gill MK, Yang M, Ryan N, Leonard H. Comparison of manic and depressive symptoms between children and adolescents with bipolar spectrum disorders. Bipolar Disorders. 2009; 11(1):52-62. [PubMed: 19133966]

Birmaher B, Brent D. Practice parameter for the assessment and treatment of children and adolescents with bipolar disorder. Journal of the American Academy of Child and Adolescent Psychiatry. 2007; 46(1):107-125. [PubMed: 17195735]

Bowden C. Strategies to Reduce Misdiagnosis of Bipolar Depression. Psychiatric Services. 2001; 52(1):51-55. [PubMed: 11141528]

Bullinger M, Brütt AL, Erhart M, Ravens-Sieberer U. Psychometric properties of the KINDL-R questionnaire: Results of the BELLA study. European Child and Adolescent Psychiatry. 2008; 17(0):125-132. [PubMed: 19132312]

Burns GL, Patterson DR. Normative Data on the Eyberg Child Behavior Inventory and Sutter-Eyberg Student Behavior Inventory: Parent and Teacher Rating Scales of Disruptive Behavior Problems in Children and Adolescents. Child \& Family Behavior Therapy. 2001; 23(1):15-28.

Cantwell DP, Lewinsohn PM, Rohde P, Seeley JR. Correspondence Between Adolescent Report and Parent Report of Psychiatric Diagnostic Data. Journal of the American Academy of Child \&amp; Adolescent Psychiatry. 1997; 36(5):610-619. [PubMed: 9136495]

Chang, K. Treatment of children and adolescents at high risk for bipolar disorder. In: Geller, B.; DelBello, M., editors. Treatment of Bipolar Disorder in Childrenand Adolescents. New York: The Guilford Press; 2008.

Cohen P, Cohen J, Aiken L, West S. The problem of units and the circumstance for POMP. Multivariate Behavioral Research. 1999; 34:315. [Article].

Cosgrove V, Roybal D, Chang K. Bipolar Depression in Pediatric Populations. Pediatric Drugs. 2013; 15(2):83-91. [PubMed: 23529869]

Dilsaver SC, Chen Y-W, Swann AC, Shoaib AM, Tsai-Dilsaver Y, Krajewski KJ. Suicidality, panic disorder and psychosis in bipolar depression, depressive-mania and pure-mania. Psychiatry Research. 1997; 73(1):47-56. [PubMed: 9463838]

Eyberg SM, Ross AW. Assessment of child behavior problems: The validation of a new inventory. Journal of Clinical Child Psychology. 1978; 7(2):113-116.

Freeman A, Youngstrom E, Freeman M, Youngstrom J, Findling R. Is Caregiver-Adolescent Disagreement Due to Differences in Thresholds for Reporting Manic Symptoms? Journal of Child and Adolescent Psychopharmacology. 2011; 21(5):425-432. [PubMed: 22040188]

Freeman A, Youngstrom E, Michalak E, Siegel R, Meyers O, Findling R. Quality of life in pediatric bipolar disorder. Pediatrics. 2009; 123(3):e446-e452. [PubMed: 19254981]

Fristad MA, Weller EB, Weller RA. The Mania Rating Scale: Can It Be Used in Children? A Preliminary Report. Journal of the American Academy of Child \& Adolescent Psychiatry. 1992; 31(2):252-257. doi: http://dx.doi.org/10.1097/00004583-199203000-00011. [PubMed: 1564026] 
Fristad MA, Weller RA, Weller EB. The Mania Rating Scale (MRS): Further Reliability and Validity Studies with Children. Annals of Clinical Psychiatry. 1995; 7(3):127-132. [PubMed: 8646272]

Geller, B.; Williams, M.; Zimerman, B.; Frazier, J. WASH-U-KSADS (Washington University in St. Louis Kiddie Schedule for Affective Disorders and Schizophrenia). St. Louis, MO: Washington University; 1996.

Geller B, Zimmerman B, Williams M, Bolhofner K, Craney J. Bipolar Disorder at Prospective FollowUp of Adults Who Had Prepubertal Major Depressive Disorder. American Journal of Psychiatry. 2001; 58:125-127. [PubMed: 11136645]

Geller B, Zimmerman B, Williams M, DelBello M, Bolhofner K, Craney J, Nickelsburg M. DSM-IV mania symptoms in a prepubertal and early adolescent bipolar disorder phenotype compared to attention-deficit hyperactive and normal controls. Journal of Child and Adolescent Psychopharmacology. 2002; 12(1):11-25. [PubMed: 12014591]

Goldstein T, Birmaher B, Axelson D, Ryan N, Strober M, Gill MK, Keller M. History of suicide attempts in pediatric bipolar disorder: Factors associated with increased risk. Bipolar Disorders. 2005; 7(6):525-535. [PubMed: 16403178]

Goldstein TR, Axelson DA, Birmaher B, Brent DA. Dialectical Behavior Therapy for Adolescents With Bipolar Disorder: A 1-Year Open Trial. Journal of the American Academy of Child \& Adolescent Psychiatry. 2007; 46(7):820-830. doi: http://dx.doi.org/10.1097/chi. 0b013e31805c1613. [PubMed: 17581446]

Joseph M, Youngstrom E, Soares J. Antidepressant-coincident mania in children and adolescents treated with selective serotonin reuptake inhibitors. Future Neurology. 2009; 4(1):87-102. [PubMed: 19884978]

Kazdin AE, French NH, Unis AS, Esveldt-Dawson K. Assessment of Childhood Depression: Correspondence of Child and Parent Ratings. Journal of the American Academy of Child Psychiatry. 1983; 22(2):157-164. [PubMed: 6841836]

Kazdin AE, Rodgers A, Colbus D. The Hopelessness Scale for Children: Psychometric characteristics and concurrent validity. Journal of Consulting and Clinical Psychology. 1986; 54(2):241. [PubMed: 3700812]

Keenan-Miller D, Peris T, Axelson D, Kowatch RA, Miklowitz DJ. Family Functioning, Social Impairment, and Symptoms Among Adolescents With Bipolar Disorder. Journal of the American Academy of Child \&amp; Adolescent Psychiatry. 2012; 51(10):1085-1094. [PubMed: 23021483]

Kowatch R, Youngstrom E, Danielyan A, Findling R. Review and metaanalysis of the phenomenology and clinical characteristics of mania in children and adolescents. Bipolar Disorders. 2005; 7(6): 483-496. [PubMed: 16403174]

Kupka RW, Altshuler LL, Nolen WA, Suppes T, Luckenbaugh DA, Leverich GS, Post RM. Three times more days depressed than manic or hypomanic in both bipolar I and bipolar II disorder1. Bipolar Disorders. 2007; 9(5):531-535. [PubMed: 17680925]

Lewinsohn P, Seeley J, Klein D. Bipolar disorders during adolescence. Acta Psychiatrica Scandinavica. 2003; 108(s418):47-50. [PubMed: 12956814]

Licht R, Gijsman H, Nolen W, Angst J. Are antidepressants safe in the treatment of bipolar depression? A critical evaluation of their potential risk to induce switch into mania or cycle acceleration. Acta Psychiatrica Scandinavica. 2008; 118(5):337-346. [PubMed: 18754834]

Lundh A, Kowalski J, Sundberg CJ, Gumpert C, Landen M. Children's Global Assessment Scale (CGAS) in a naturalistic clinical setting: Inter-rater reliability and comparison with expert ratings. Psychiatry Research. 2010; 177(1-2):206-210. [PubMed: 20334931]

Lynch FL, Clarke GN. Estimating the Economic Burden of Depression in Children and Adolescents. American Journal of Preventive Medicine. 2006; 31 Supplement 1(6):143-151.

McElroy S, Strakowski S, West S, Keck P Jr. McConville B. Phenomenology of adolescent and adult mania in hospitalized patients with bipolar disorder. American Journal of Psychiatry. 1997; 154(1):44-49. [PubMed: 8988957]

Michalak EE, Murray G, Young AH, Lam RW. Burden of Bipolar Depression. [Article]. CNS Drugs. 2008; 22(5):389-406. [PubMed: 18399708] 
Miklowitz DJ, Axelson DA, Birmaher B, George EL, Taylor DO, Schneck CD, Brent DA. FamilyFocused Treatment for adolescents with bipolar disorder: Results of a 2-year randomized trial. Journal of Affective Disorders. 2004; 82(Suppl 1):S113. [PubMed: 15571785]

Mitchell PB, Malhi GS. Bipolar depression: phenomenological overview and clinical characteristics. Bipolar Disorders. 2004; 6(6):530-539. [PubMed: 15541069]

Moreno C, Laje G, Blanco C, Jiang H, Schmidt AB, Olfson M. National Trends in the Outpatient Diagnosis and Treatment of Bipolar Disorder in Youth. Archives of General Psychiatry. 2007; 64(9):1032-1039. [PubMed: 17768268]

Moretti MM, Fine S, Haley G, Marriage K. Childhood and Adolescent Depression: Child-report versus Parent-report Information. Journal of the American Academy of Child Psychiatry. 1985; 24(3): 298-302. [PubMed: 4008820]

Nivoli A, Murru A, Goikolea J, Crespo J, Montes J, Gonzalez-Pinto A, Vieta E. New treatment guidelines for acute bipolar mania: A critical review. Journal of Affective Disorders(0). 2011

Olfson M, Blanco C, Liu L, Moreno C, Laje G. National trends in the outpatient treatment of children and adolescents with antipsychotic drugs. Archives of General Psychiatry. 2006; 63(6):679-685. [PubMed: 16754841]

Pavuluri M, Henry D, Devineni B, Carbray J, Birmaher B. Child mania rating scale: development, reliability, and validity. Journal of the American Academy of Child \& Adolescent Psychiatry. 2006; 45(5):550-560. [PubMed: 16601399]

Piers, EV.; Harris, DB.; Herzberg, DS. The Piers-Harris children's self concept scale-Second Edition. Los Angeles, CA: Western Psychological Services; 2002.

Piers EV, Herzberg DS. Piers-Harris Children's Self-Concept Scale, (The Way I Feel About Myself). 1969

Posner K, Brent D, Lucas C, Gould M, Stanley B, Brown G, Oquendo M. Columbia-Suicide Severity Rating Scale (C-SSRS). 2008

Posner K, Brown GK, Stanley B, Brent DA, Yershova KV, Oquendo MA, Shen S. The ColumbiaSuicide Severity Rating Scale: initial validity and internal consistency findings from three multisite studies with adolescents and adults. American Journal of Psychiatry. 2011; 168(12): 1266-1277. [PubMed: 22193671]

Post RM. The impact of bipolar depression. The Journal of Clinical Psychiatry. 2005; 66(5):5. [PubMed: 16038596]

Post RM. Kindling and sensitization as models for affective episode recurrence, cyclicity, and tolerance phenomena. Neuroscience \&amp; Biobehavioral Reviews. 2007; 31(6):858-873. [PubMed: 17555817]

Power MJ, de Jong F, Lloyd A. The Organization of the Self-Concept in Bipolar Disorders: An Empirical Study and Replication. Cognitive Therapy and Research. 2002; 26(4):553-561.

Poznanski E, Freeman L, Mokros H. Children's Depression Rating Scale-Revised. Psychopharmacology Bulletin. 1985; 21:979-989.

Poznanski EO, Grossman JA, Buchsbaum Y, Banegas M, Freeman L, Gibbons R. Preliminary Studies of the Reliability and Validity of the Children's Depression Rating Scale. Journal of the American Academy of Child Psychiatry. 1984; 23(2):191-197. doi: http://dx.doi.org/ 10.1097/00004583-198403000-00011. [PubMed: 6715741]

Ravens-Sieberer, U.; Bullinger, M. Revised Version, Manual. Berlin, Germany: KINDL; 2000. KINDL: Questionnaire for Measuring Health Related Quality of Life in Children and Adolescents.

Schraufnagel C, Brumback R, Harper C, Weinberg W. Affective illness in children and adolescents: Patterns of presentation in relation to pubertal maturation and family history. Journal of Child Neurology. 2001; 16(8):553-561. [PubMed: 11510924]

Shaffer D, Gould MS, Brasic J, Ambrosini P, Fisher P, Bird H, Aluwahlia S. A Children's Global Assessment Scale (CGAS). Archives of General Psychiatry. 1983; 40(11):1228-1231. [PubMed: 6639293]

Sidor, M.; MacQueen, G. Antidepressants for the Acute Treatment of Bipolar Depression: A Systematic Review and Meta-Analysis. Vol. Vol. 72. Memphis, TN, ETATS-UNIS: Physicians Postgraduate Press; 2011. 
Soutullo C, Chang K, D1ez-Sua'rez A, Figueroa-Quintana A, Escamilla-Canales I, Rapado-Castro M, Ortuno F. Bipolar disorder in children and adolescents: international perspective on epidemiology and phenomenology. Bipolar Disorders. 2005; 7:497-506. [PubMed: 16403175]

Spearing MK, Post RM, Leverich GS, Brandt D, Nolen W. Modification of the Clinical Global Impressions (CGI) scale for use in bipolar illness (BP): the CGI-BP. Psychiatry Research. 1997; 73(3):159-171. doi: http://dx.doi.org/10.1016/S0165-1781(97)00123-6. [PubMed: 9481807]

Spirito A, Williams C, Stark L, Hart K. The Hopelessness Scale for Children: Psychometric properties with normal and emotionally disturbed adolescents. Journal of Abnormal Child Psychology. 1988; 16(4):445-458. [PubMed: 3221033]

Strober M. The Course of Major Depressive Disorder in Adolescents: I. Recovery and Risk of Manic Switching in a Follow-up of Psychotic and Nonpsychotic Subtypes. Journal of the American Academy of Child and Adolescent Psychiatry. 1993; 32(1):34-42. [PubMed: 8428882]

Tondo L, Vazquez G, Baldessarini RJ. Mania associated with antidepressant treatment: comprehensive meta-analytic review. Acta Psychiatrica Scandinavica. 2010; 121(6):404-414. [PubMed: 19958306]

Trumbull HC. The sorrows of children. 1898:239-246.

Wee H, Lee W, Ravens-Sieberer U, Erhart M, Li S. Validation of the english version of the KINDL® generic children's health-related quality of life instrument for an Asian population - results from a pilot test. Quality of Life Research. 2005; 14(4):1193-1200. [PubMed: 16041914]

West AE, Jacobs RH, Westerholm R, Lee A, Carbray J, Heidenreich J, Pavuluri MN. Child and family-focused cognitive-behavioral therapy for pediatric bipolar disorder: pilot study of group treatment format. Journal of the Canadian Academy of Child and Adolescent Psychiatry. 2009; 18(3):239. [PubMed: 19718425]

Wozniak J, Biederman J, Kiely K, Ablon JS, Faraone S, Mundy E, Mennin D. Mania-like symptoms suggestive of childhood-onset bipolar disorder in clinically referred children. Journal of the American Academy of Child and Adolescent Psychiatry. 1995; 34(7):867-876. [PubMed: 7649957]

Wozniak J, Spencer T, Biederman J, Kwon A, Monuteaux M, Rettew J, Lail K. The clinical characteristics of unipolar vs. bipolar major depression in ADHD youth. Journal of Affective Disorders. 2004; 82(Supplement0):S59-S69. [PubMed: 15571791]

Young M, Fristad M. Evidence Based Treatments for Bipolar Disorder in Children and Adolescents. Journal of Contemporary Psychotherapy. 2007; 37(3):157-164.

Young R, Biggs J, Ziegler V, Meyer D. A rating scale for mania: reliability, validity and sensitivity. The British Journal of Psychiatry. 1978; 133(5):429-435. [PubMed: 728692]

Youngstrom E, Findling R, Calabrese J. Who are the comorbid adolescents? Agreement between psychiatric diagnosis, youth, parent, and teacher report. Journal of Abnormal Child Psychology. 2003; 31(3):231-245. [PubMed: 12774858]

Youngstrom E, Findling R, Calabrese J. Effects of adolescent manic symptoms on agreement between youth, parent, and teacher ratings of behavior problems. Journal of Affective Disorders. 2004; 82(1001):S5-S16. [PubMed: 15571790]

Youngstrom E, Findling R, Calabrese J, Gracious B, Demeter C, DelPorto Bedoya D, Price M. Comparing the diagnostic accuracy of six potential screening instruments for bipolar disorder in youths aged 5 to 17 years. Journal of the American Academy of Child and Adolescent Psychiatry. 2004; 43(7):847-858. [PubMed: 15213586]

Zito J, Safer D, dosReis S, Gardner J, Magder L, Soeken K, Riddle M. Psychotropic practice patterns for youth: A 10-year perspective. Archives of Pediatrics \& Adolescent Medicine. 2003; 157(1): 17-25. [PubMed: 12517190] 
Table 1

Demographic and diagnostic information

\begin{tabular}{lrr} 
& Percent & \\
\cline { 2 - 3 } Ethnicity & Female & $\mathbf{4 2}$ \\
& White & 60 \\
Black & 29 \\
Hispanic & 5 \\
Diagnosis & Other & 2 \\
& & \\
& BP I & 41 \\
& BP II & 2 \\
BP NOS & 57 \\
& & \\
Comorbid & ADHD & 74 \\
& Anxiety & 33 \\
& ODD & 39 \\
& Conduct Disorder & 4 \\
\hline
\end{tabular}

$J$ Affect Disord. Author manuscript; available in PMC 2014 September 25. 


\section{Table 2}

Descriptive statistics for variables of interest; $\mathrm{N}=54$

\begin{tabular}{rccc} 
& Mean & SD & Range \\
\hline Child's age & 9.10 & 1.59 & $7-13$ \\
YMRS & 12.28 & 5.71 & $2-34$ \\
CDRS & 39.86 & 10.73 & $23-65$ \\
CMRS & 23.68 & 11.09 & $1-48$ \\
CBDRS & 18.84 & 10.33 & $2-45$ \\
C-GAS & 49.36 & 4.73 & $41-61$ \\
CGI & 3.90 & 0.57 & $2-6$ \\
ECBI Intensity Scale & 156.11 & 35.09 & $89-305$ \\
ECBI Problem Scale & 21.50 & 7.33 & $0-33$ \\
PHSCS Total & 27.00 & 9.59 & $8-51$ \\
KINDL Total Score & 3.56 & 0.54 & $2.04-4.38$ \\
Parent KINDL Total Score & 3.39 & 0.44 & $2.38-4.38$ \\
Hopelessness Scale for Children & 4.58 & 2.90 & $0-11$ \\
\hline & $n$ & $\%$ &
\end{tabular}

Columbia Suicide Severity Rating Scales

Lifetime Suicide Attempts $\quad 4 \quad 7$

Lifetime Suicidal Ideation $\quad 42 \quad 76$

Active Suicidal Ideation $\quad 28 \quad 51$

Lifetime Suicidal Ideation with Method $19 \quad 35$

Lifetime Suicidal Ideation with Intent $\quad 12 \quad 22$

Lifetime Suicidal Ideation with Plan $\quad 9 \quad 16$

Lifetime Suicidal Behavior $\quad 14 \quad 26$ 